\title{
Pigments Extraction of Treated Hybrid Microalgae-Activated Sludge
}

\author{
A. I. Dabai ${ }^{\mathrm{a}, \mathrm{b}}$, K. Mohammed ${ }^{\mathrm{a}, *}$ \\ ${ }^{a}$ Department of Civil Engineering, Bayero University Kano, Kano State, NIGERIA. \\ ${ }^{b}$ Department of Civil Engineering Technology, Federal Polytechnic, Kaura Namoda, Zamfara State, NIGERIA.
}

\begin{abstract}
Microalgae have the ability to grow in wastewater, remove heavy metal ions and pollutants, and can be used to produce renewable energy alternatives such as biofuels, biogas, biomethane and biohydrogen. Algae can also produce high-value non-energy pigments such as chlorophylls and carotenoids that are used in feeds, colorants, textiles, nutraceutical and pharmaceutical industries. Methanol extraction method was employed to extract the pigments from microalgal specie Chlorella vulgaris spectrophotometrically after bioremediation of synthetic tannery wastewater (STWW) in stirred-tank photobioreactors (STPBRs) operated at about $580 \mu \mathrm{mol} . \mathrm{m}^{-2} \cdot \mathrm{s}^{-1}$ and 100 rpm for 12:12 light-dark cycles. The maximum Chl a, Chl b, total carotenoids and total pigments were determined to be 35.5091, 8.6315, 1.9521 and $41.850 \mu \mathrm{g} / \mathrm{L}$, respectively and highest content increment of 66.91, 66.97, 69.11 and $69.38 \%$ in reactor $A, B, C$ and $D$, respectively, was achieved during the bioremediation process.
\end{abstract}

Keywords: photobioreactors, pigments, chlorophyl, carotenoids, bioremediation

\section{INTRODUCTION}

Microalgae are widely employed in bioremediation processes due to their even distribution, high tolerance to environmental conditions [1] as well as their modes of nutrition and metabolic activities [2]. Algae can easily grow in the presence of moisture thereby utilizing the available energy from light to photosynthesize [3] and increase in concentration within a short period of time [4], accumulate pollutants through the cell surface [5] and absorb positively charged heavy metal ions present in the wastewater stream to their cell walls by anionic ligands [6, 7]. Several types of research reported the extraction of energy molecules from algal biomass that range from bioethanol, biodiesel, biogas, biohydrogen, methane and many other valuable energy alternatives $[1,8,9]$ that make algal bioremediation more attractive. Despite these advances in the treatment prospects, the extraction of energy molecules from microalgae is associated with some setbacks including low productivities and high extraction cost that hinders the full utilization of algal renewable energy alternatives compared to conventional fossil fuels.

Several studies highlighted some ways to minimising the production cost of algal biomass extracts as [2] suggest that mass cultivation of microalgae may reduce the production cost and

${ }^{*}$ Corresponding author (Tel: +234(0) 806059 8055)

Email addresses: ask4aminu@gmail.com (A. I. Dabai), kmohammed.civ@buk.edu.ng (K. Mohammed) will also increase the quantity of valuable energy molecules extractions. [5, 10-12] indicated increased treatment efficiencies and microbial biodegradability when activated sludge was incorporated into the microalgal treatment due to symbiotic relationship that exist between algae and bacteria by production of oxygen as by-product of photosynthesis which was needed by bacterial cells for waste degradation. Also production of carbon-dioxide as a result of bacterial degradation termed as mineralization by [13], which was cheaply utilized by microalgae in photosynthesis [3]. These treatment approaches enhance the productivity and reduce the cost of stirring accounting for about $40-75 \%$ overall treatment cost $[14,15]$.

The potential high value non-energy molecules comprising pigments such as chlorophylls and carotenoids; lipids, proteins and many more are useful for food, nutraceutical, pharmaceuticals, personal care product industries [16, 17]. However, despite this wide application of non-energy molecules extracted from algae (e.g. chlorophylls, carotenoids, etc.), only little attention was paid to it with regards to its full extraction and utilization, which in turn may decrease the carbon footprint of microalgal cultivation system as well as reduce algal cultivation cost by increasing the quantity of extracted molecules.

Microalgae as photosynthetic organisms contain chlorophylls and carotenoids as pigments that are termed lipophilic molecules which when extracted can easily replace conventional synthetic colouring pigments. Their capability to 
replace synthetic pigments is due to the growing concerns with toxicity of synthetic pigments and the simplicity of extraction approach of these naturally occurring organic pigments as well as their wide applications [18, 19]. Recently, various methods were employed for the extraction of microalgal pigments and these include $90 \%$ Acetone [20, 21], 100\% Methanol extraction method $[8,19,22]$, high performance liquid chromatography [23], mechanical extraction [24] and ultrasound method [25].

The choice of extraction method depends on solvent simplicity, compatibility, cost, yield, and inertness that does not alter the microbial cell composition [24, 26] and as such, organic solvent extraction methods are considered as the best alternative [19, 21,27]. Methanol was found to be one of the most efficient solvents to extract multiple pigments from algae due to its lysis property in destruction of cell walls that increase the extraction yield [19]. In the current study, methanol extraction process was adopted in order to quantify the amount of chlorophyll a and b, total carotenoids as well as total pigments content during the treatment of synthetic tannery wastewater (STWW) using microalgal specie Chlorella vulgaris in a hybrid microalgae-activated sludge system in semicontinuous stirred-tank photobioreactors, for a period of three weeks.

\section{MATERIALS AND METHODS}

\subsection{Synthetic Tannery Wastewater (STWW)}

The 50,100 and $150 \mathrm{mg} / \mathrm{L}$ concentrations of STWW was prepared by diluting the specific weight of potassium dichromate with distilled water to obtain the specified hexavalent chromium concentration as described by [6]. The entire chemicals used were of analytical grade.

\subsection{Algal Cultivation}

Chlorella vulgaris was isolated and cultured in $1 \mathrm{~L}$ volumetric flask using Bold Basal's Medium (BBM) in accordance with [28], in Herbarium Laboratory, Department of Plant Biology, Bayero University, Kano, for two weeks. This culture was illuminated under $20 \mathrm{~W}$ white fluorescent bulb in a mechanical shaker at 200rpm. During this period, the algal biomass concentration was estimated using a haemocytometer as described by [29].

\subsection{Stirred-Tank Photobioreactors (STP. BRs) Operation}

The microalgal culture was up-scaled in three STPBRs in accordance with $[3,10]$. The $21 \mathrm{~L}$ STPBR consisting of $16 \mathrm{~L}$ working volume was illuminated using red light-emitting diodes (LEDs) at an optimum irradiance of $582.7 \mu \mathrm{mol} . \mathrm{m}^{-2} . \mathrm{s}^{-1}$, $100 \mathrm{rpm}$ for 12:12 light-dark cycles. Three STPBRs were inoculated with $10 \%$ activated sludge culture of the BBM-microalgal culture and labelled as B, C and D. Each of 50,100 and 150 $\mathrm{mg} / \mathrm{L}$ of STWW was introduced to B, C and D respectively; while a separate reactor A was inoculated using $50 \mathrm{mg} / \mathrm{L}$ of STWW in the dark with
Table 1: Pigments extraction profiles for reactor A.

\begin{tabular}{lcccc}
\hline Test No & Chl a & Chl b & TC & TP \\
\hline 1 & 10.1584 & 2.2904 & 0.4842 & 12.9331 \\
2 & 10.9242 & 2.3956 & 0.4399 & 13.7598 \\
3 & 11.9633 & 2.2833 & 0.5962 & 14.8429 \\
4 & 14.2478 & 2.7390 & 0.6939 & 17.6808 \\
5 & 16.8851 & 2.2664 & 1.2211 & 20.3727 \\
6 & 18.2573 & 4.2255 & 0.1531 & 22.6360 \\
7 & 20.1488 & 4.1782 & 0.3780 & 24.7051 \\
8 & 22.6096 & 3.2872 & 1.1295 & 27.0264 \\
9 & 23.3341 & 4.3809 & 0.7069 & 28.4220 \\
10 & 28.6614 & 6.1221 & 0.2762 & 35.0597 \\
11 & 28.5356 & 6.5390 & 0.0657 & 35.1405 \\
12 & 28.3606 & 6.533 & 0.0530 & 34.9474 \\
13 & 28.3120 & 0.5358 & 0.0498 & 31.8905 \\
\hline
\end{tabular}

no enhancements of aeration and illumination. The STPBRs were wrapped with aluminium foil to concentrate light internally.

\subsection{Analytical Tests}

Samples were collected from each reactor every 2 days and analysed for chlorophylls a and b $(\mathrm{Chl}$ a and b), total carotenoids (TC) and total pigment (TP) contents of the culture for the experimental duration in accordance with [8].

\subsection{Pigment Extraction}

A sample of $1.5 \mathrm{~mL}$ was collected from each STPBR and centrifuged at $17,000 \mathrm{xg}$ for $5 \mathrm{mins}$, after which the supernatant was decanted. The algal pellets were then suspended in $1.5 \mathrm{~mL}$ methanol and incubated at $45^{\circ} \mathrm{C}$ for 30 mins. The methanol extracts were transferred to plastic cuvettes for spectrophotometric measurements at 470,653 and $666 \mathrm{~nm}$ wavelengths and their respective absorbance values as A470, A653 and A666 were recorded using UV-Vis spectrophotometer and Chl a, Chl b, TC and TP were estimated from the following equations by $[8,30]$.

$$
\begin{gathered}
C h l a(\mu g / L)=15.65 A_{666}-7.34 A_{653} \\
C h l b(\mu g / L)=27.05 A_{653}-11.21 A_{666} \\
T C(\mu g / L)=\left[1000 A_{470}-2.86 C h l a-129.2 C h l b\right] / 221 \\
T P(\mu g / L)=C h l a+C h l b+T C
\end{gathered}
$$

\section{RESULTS AND DISCUSSION}

Absorbance was recorded in triplicates and their mean values were used for the estimation of Chl a, Chl b, TC and TP from equations 1-4 as presented in Tables $1-4$ for the four reactors. In reactor $\mathrm{A}$, the initial $\mathrm{Chl}$ a concentration at the beginning of the experiment was found to be $10.1585 \mu \mathrm{g} / \mathrm{L}$ which increased continuously up to about first 18 days of the treatment to a maximum of $28.6614 \mu \mathrm{g} / \mathrm{L}$ and then declined to concentration of $28.3121 \mu \mathrm{g} / \mathrm{L}$ at the end of the three weeks treatment period as shown in Table 1.

The Chl b concentration also increased from $2.2904 \mu \mathrm{g} / \mathrm{L}$ to a maximum of $6.5391 \mu \mathrm{g} / \mathrm{L}$ within the period of 20 days and then decreased to 5.5358 


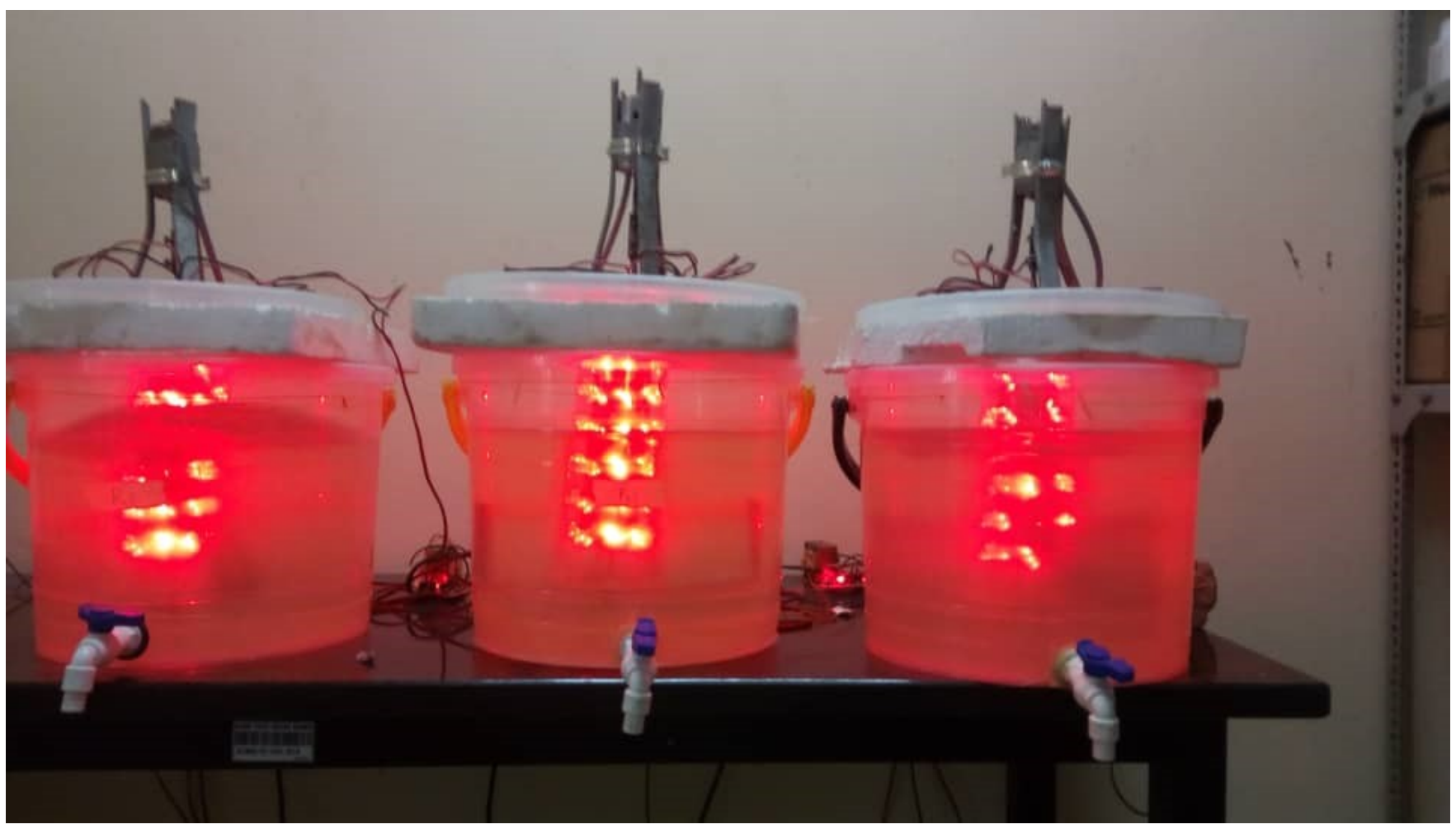

Figure 1: Stirred-Tank Photobioreactors Set-up.

Table 2: Pigments extraction profiles for reactor B.

\begin{tabular}{lcccc}
\hline Test No & Chl a & Chl b & TC & TP \\
\hline 1 & 10.8563 & 1.8558 & 0.7564 & 13.43 \\
2 & 11.0347 & 2.3601 & 0.4955 & 13.8904 \\
3 & 12.8568 & 2.0574 & 0.8344 & 15.7486 \\
4 & 14.3221 & 3.2088 & 0.4319 & 17.9629 \\
5 & 16.9283 & 3.8263 & 0.3403 & 21.0950 \\
6 & 18.2573 & 4.2255 & 0.1531 & 22.6360 \\
7 & 20.2338 & 4.4224 & 0.2930 & 24.9493 \\
8 & 22.2256 & 4.2379 & 0.7687 & 27.2322 \\
9 & 23.3341 & 4.3809 & 0.7069 & 28.4220 \\
10 & 32.6555 & 3.7623 & 1.7036 & 38.1215 \\
11 & 32.8066 & 3.7631 & 1.7284 & 38.2981 \\
12 & 31.4983 & 4.6348 & 1.1407 & 37.2739 \\
13 & 31.1109 & 3.9420 & 1.0542 & 33.9787 \\
\hline
\end{tabular}

$\mu \mathrm{g} / \mathrm{L}$ after the three weeks. Total carotenoids being the function of chlorophylls content was initially found to be $0.4828 \mu \mathrm{g} / \mathrm{L}$ and then reached a maximum of $1.1298 \mu \mathrm{g} / \mathrm{L}$ at 14 days and subsequently reduced to $0.0498 \mu \mathrm{g} / \mathrm{L}$ at the end of the three weeks period. The total pigments content in A been summation of the all the other extracted pigments, it was found to increase continuously from the initial $12.9332 \mu \mathrm{g} / \mathrm{L}$ to the highest of $35.1405 \mu \mathrm{g} / \mathrm{L}$ and then decreased to 31.8905 $\mu \mathrm{g} / \mathrm{L}$.

In reactor $\mathrm{B}$ with enhancement of light and stirring, the $\mathrm{Chl}$ a concentration reaches highest growth of $32.8066 \mu \mathrm{g} / \mathrm{L}$ within the 20 days of the treatment from the initial value of 10.8564 $\mu \mathrm{g} / \mathrm{L}$ and then decreased to $31.1109 \mu \mathrm{g} / \mathrm{L}$ as indicated by Table 2 . The Chl b increased from the
Table 3: Pigments extraction profiles for reactor C.

\begin{tabular}{lcccc}
\hline Test No & Chl a & Chl b & TC & TP \\
\hline 1 & 10.8475 & 2.1673 & 0.5925 & 13.6074 \\
2 & 11.1085 & 2.4597 & 0.5449 & 14.1132 \\
3 & 13.2709 & 2.4363 & 0.7251 & 16.4324 \\
4 & 15.1147 & 3.4474 & 0.3545 & 18.9167 \\
5 & 17.9449 & 4.1224 & 0.2853 & 22.3527 \\
6 & 18.6206 & 4.4665 & 0.1161 & 23.2033 \\
7 & 20.8896 & 4.2359 & 0.5247 & 25.6503 \\
8 & 22.6910 & 4.4275 & 0.7107 & 27.8293 \\
9 & 22.9372 & 8.6314 & 1.51938 & 30.0493 \\
10 & 35.1164 & 2.1739 & 3.1660 & 40.4564 \\
11 & 34.4310 & 3.8635 & 1.8387 & 40.1332 \\
12 & 34.3063 & 3.6259 & 1.9521 & 39.8844 \\
13 & 33.1684 & 1.1285 & 1.5248 & 38.5745 \\
\hline
\end{tabular}

initial value of $1.8558 \mu \mathrm{g} / \mathrm{L}$ to a highest value of $4.6348 \mu \mathrm{g} / \mathrm{L}$ and then decreased to $3.9420 \mu \mathrm{g} / \mathrm{L}$. The total carotenoids increased to a maximum of $1.7285 \mu \mathrm{g} / \mathrm{L}$ from $0.7564 \mu \mathrm{g} / \mathrm{L}$ and then declined to $1.0543 \mu \mathrm{g} / \mathrm{L}$ at the end of the treatment. The total pigment extracted from reactor $\mathrm{B}$, ranges from $13.4686 \mu \mathrm{g} / \mathrm{L}$ to $38.2981 \mu \mathrm{g} / \mathrm{L}$ and then decreased to $33.9787 \mu \mathrm{g} / \mathrm{L}$ after the three weeks treatment period.

$\mathrm{Chl}$ a concentration from reactor $\mathrm{C}$ increased to a highest value of $35.1164 \mu \mathrm{g} / \mathrm{L}$ from $10.8475 \mu \mathrm{g} / \mathrm{L}$ during the first 16 days of the treatment as shown in Table 3, and then decreased to $33.1684 \mu \mathrm{g} / \mathrm{L}$ after three weeks.

In reactor $\mathrm{D}$, the concentration of $\mathrm{Chl}$ a increased to a maximum of $35.5091 \mu \mathrm{g} / \mathrm{L}$ from an initial value of $10.8734 \mu \mathrm{g} / \mathrm{L}$ at 18 days and then 
Table 4: Pigments extraction profiles for reactor $\mathrm{D}$.

\begin{tabular}{lcccc}
\hline Test No & Chl a & Chl b & TC & TP \\
\hline 1 & 10.8734 & 2.2577 & 0.5258 & 13.6569 \\
2 & 12.0715 & 1.7917 & 0.9727 & 14.8360 \\
3 & 13.5980 & 2.4853 & 0.8235 & 16.9069 \\
4 & 15.8561 & 3.1778 & 0.5523 & 19.5863 \\
5 & 17.9449 & 4.1224 & 0.2853 & 22.3527 \\
6 & 18.9883 & 4.5518 & 0.2832 & 23.8234 \\
7 & 21.3791 & 4.4301 & 0.5179 & 26.3273 \\
8 & 22.6964 & 5.0121 & 0.5091 & 28.2176 \\
9 & 26.4497 & 3.2606 & 1.7197 & 31.4302 \\
10 & 35.5091 & 2.3067 & 3.8389 & 41.6548 \\
11 & 35.2874 & 3.4026 & 3.1604 & 41.8505 \\
12 & 33.5127 & 4.0419 & 2.6739 & 40.2285 \\
13 & 32.1789 & 2.7308 & 2.5934 & 37.5031 \\
\hline
\end{tabular}

decreased to $32.1789 \mu \mathrm{g} / \mathrm{L}$ after three weeks of the treatment. Chl b increased to $5.0121 \mu \mathrm{g} / \mathrm{L}$ from $2.2577 \mu \mathrm{g} / \mathrm{L}$ during the first 2 weeks of the treatment and then reduced to $2.7308 \mu \mathrm{g} / \mathrm{L}$ at the end of the bioremediation process and the total carotenoids extracted from reactor $\mathrm{D}$, ranged from the initial concentration of $0.5258 \mu \mathrm{g} / \mathrm{L}$ to a highest value of $3.8389 \mu \mathrm{g} / \mathrm{L}$ within the 18 days of the treatment period and then declined to $2.5934 \mu \mathrm{g} / \mathrm{L}$ at the end of the treatment.

The total pigments extracted in $\mathrm{D}$ ranges from a minimum concentration of $13.6569 \mu \mathrm{g} / \mathrm{L}$ to a maximum of $41.8505 \mu \mathrm{g} / \mathrm{L}$ at 18 days and then decreased to moderate value of $37.5031 \mu \mathrm{g} / \mathrm{L}$ after the bioremediation process as shown in Table 4

Chlorophyll concentration depends on the dominance of different algal group in the biomass population and its changes in content occurred during ontogenesis of individual cell and also the development of the whole biomass [31]. The Chl a concentration in each reactor is about $80 \%$ of the total pigment that can be observed from Table 2-4, and this confirmed the assertion that the $\mathrm{Chl}$ a is main photosynthetic pigment and that some algae contain only Chl a like Nanochloropsys gaditana [19].

Chl a content were found to increase throughout the growth phase of Chlorella vulgaris sp in all the reactors and increases from its initial concentrations of about $10 \mu \mathrm{g} / \mathrm{L}$ to a maximum of 35.5091 $\mu \mathrm{g} / \mathrm{L}$, with percentage increment of $66.91,66.97$, 69.11 and $69.38 \%$ from reactor $\mathrm{A}, \mathrm{B}, \mathrm{C}$ and $\mathrm{D}$ respectively. The lowest percentage increase was observed in control reactor A with no enhancements of stirring and illumination. The increase in the $\mathrm{Chl}$ a content in STPBRs increases with increase in the quantity of STWW of 50,100 and $150 \mathrm{mg} / \mathrm{L}$ in reactors $\mathrm{B}, \mathrm{C}$ and $\mathrm{D}$ respectively. This increase as a result of increasing concentration of wastewater which may be connected to the fact that the Chl content was not directly proportional to the illumination as described by [20] that the maximum Chl concentration was found in deeper hypolimnion region of the oligotrophic lake.

A reasonable increase in $\mathrm{Chl}$ a concentration was observed in reactor $\mathrm{A}$ despite the absence of light and mixing and this might be due to natural aeration that exist between microalgal cells and bacterial cells in efficient exchange of gases (carbon dioxide and oxygen). As symbiotic relationships exist between these organisms and as well as the fact that Chl concentration does not depend only on light intensities, [31] ascertained that periods with higher intensities of light were associated with averagely low concentrations of $\mathrm{Chl}$ content and also the Chl proliferation was also related to nutrients availability and taxonomic composition of the biomass content [20].

Relatively lower total Chl content of $75.68 \%$ of the total biovolume from green microalgae was reported by [31]. While [25] shows an increase in Chl a content of about $58.33 \%$ and [32] reported a relatively higher increase in Chl a content of about 95 and $77.77 \%$ for mesotrophic lakes and eutrophic lakes respectively and [23] reported a maximum Chl a concentration of $82.14 \%$.

On the other hand, Chl b content in all the four reactors was found to be much lower than the $\mathrm{Chl}$ a, with an average of $15.99 \%$ compared to about $80 \%$ of Chl a content. Remarkable increase in $\mathrm{Chl}$ b content was also observed from all the reactors in the treatment, as the concentrations ranged from $64.97,57.64,74.96$ and $54.95 \%$ for reactors $\mathrm{A}, \mathrm{B}, \mathrm{C}$ and $\mathrm{D}$ respectively, within $16-20$ days of the treatment as also [33] reported a considerable increase in Chl a content was obtained in the 16th day of the treatment. A much less percentage increase in Chl content was observed in reactor D which may be affected by taxonomic culture conditions.

Carotenoids have been described as photosynthetic accessory pigments and play a protective role against oxygen radicals released during photosynthesis from damaging DNA by [34], a reasonable increase in total carotenoids were observed across all the reactors and ranged from 57.12, $56.24,81.28$ and $86.30 \%$ from reactor $\mathrm{A}, \mathrm{B}, \mathrm{C}$ and D respectively from 14-20 days of the treatment. The highest total carotenoid concentrations were found in reactors with higher wastewater strength of 100 and $150 \mathrm{mg} / \mathrm{L}$. The maximum total carotenoid content of $57.12 \%$ was attained within the second week of the treatment in control reactor A.

[35] reported similar total carotenoid content increase of $64.15 \%$ which was lower than the highest total carotenoid concentrations obtained in reactor $\mathrm{C}$ and $\mathrm{D}$, despite having higher concentration of STWW. Moreover, [36] extracted carotenoid components as $\beta$-Carotene and Lutein, with highest values for $\beta$-Carotene and Lutein to be 15.9 and $5.2 \mu \mathrm{g} / \mathrm{kg}$ respectively and, while a maximum Lutein increase of about $93.19 \%$, and also 0.95 and $0.31 \mathrm{mg}$ per $100 \mathrm{~g}$ of sample for carotene and xanthophyll was reported by [34] which were part of the total carotenoids extracted. These were specialized experiment designed for the purpose of pigment extraction whereas in this current study, the extraction of pigments was performed after STWW bioremediation process.

The quantities of pigments are extracted during the hybrid microalgae-activated sludge bioremediation of synthetic tannery wastewater cou- 
pled with reasonable higher removal efficiencies of $\mathrm{Cr}(\mathrm{VI})$ ions, ammonium, nitrate and phosphates. However, these findings were limited to only co-culture of algae and bacteria to exploit their symbiotic relationship, but the capability of mono-culture of algae and bacteria to produce these pigments should be investigated and real tannery wastewater should also be employed, with the same or different treatment approach as contained in present study.

\section{CONCLUSION}

Following the successful bioremediation of STWW using a hybrid microalgae-activated sludge treatment system with $C$. vulgaris specie, the maximum Chl a, Chl b, total carotenoids and total pigments of $35.5091,8.6315,1.9521$ and $41.8505 \mu \mathrm{g} / \mathrm{L}$ respectively were extracted and the highest pigments increment attained was 66.91, $66.97,69.11$ and $69.38 \%$ in reactors A, B, C and D after the three weeks bioremediation process. It was also observed that the highest growth rates of the biomass were observed in reactor $\mathrm{C}$ and $\mathrm{D}$ with highest concentration of STWW.

\section{ACKNOWLEDGEMENT}

The authors are grateful to $\mathrm{Mr}$ Bahaudden Sa'id Adam of Herbarium Laboratory, Department of Plant Biology, Bayero University, Kano, Mr Musa Garba Beli of Central Laboratory Complex, Bayero University, Kano, Engr. Zubairu Garba, Mr Auwal Musa and Mudassir Yahya Ibrahim of Tamburawa Water Works for their assistance in microalgal culturing, cultivation, monitoring and help in the analyses.

\section{References}

[1] S. Ojanen, E. Tyystjärvi, and K. Jokinen, "Utilization of microalgae in industrial symbiosis, focus on finland,", Nat. Resour. bioeconomy Stud., vol. 33, no. 33, 2017.

[2] F. Gatien, S. Jean-Francois, F. Delrue, D. Álvarez Díaz, and D. Fon-Sing, "The Environmental Biorefinery: Using Microalgae to Remediate Wastewater, a Win-Win Paradigm," Energies, vol. 9, no. 132, pp. 1-19, 2016.

[3] K. Mohammed, P. Sallis, S. Ahammad, and C. Mota, "Energy-efficient stirred-tank photobioreactors for simultaneous carbon capture and municipal wastewater treatment,"Water Sci. Technol., vol. 6, no. 10, pp. 2106$2112,2014$.

[4] Y. Luo, P. Le-clech, and R. Henderson, "Simultaneous microalgae cultivation and wastewater treatment in submerged membrane photobioreactors: A review," $A L G A L, 2016$.

[5] K. Mohammed and C. Mota, "Microalgae and sustainable wastewater treatment: A Review," Bayero J. Pure Appl. Sci., vol. 11, no. 1, p. 408, 2019.

[6] C. G. Donmez, A. Ozturk, T. Kutsal, and Z. Akzu, "Comparative study on heavy metal Biosorption characteristics of some algae A comparative study on heavy metal biosorption characteristics of some algae," Process Biochem., vol. 34, pp. 885-892, 1999.

[7] P. Subashini and P. Rajiv, "Chlorella vulgaris DPSF 01: A unique tool for removal of toxic chemicals from tannery wastewater," African J. Biotechnol., vol. 17, no. 8, pp. 239-248, 2018.

[8] L. Linarez, K. Falfan, and C. Ramirez-lopez, “"microalgal biomass: A biorefinery approach," in Biomass Volume Estimation and Valorization for Energy, 2016, p. 13.
[9] S. Zhu, W. Huang, J. Xu, J. Wang, Z. Xu, and Z. Yuan, "'Metabolic changes of starch and lipid triggered by nitrogen starvation in the microalga Chlorella zofingiensis," Bioresour. Technol., vol. 152, pp. 292-98, 2014.

[10] K. Mohammed, Z. Ahammad, P. Sallis, and C. Mota, "Optimisation of red light-emitting diodes irradiance for illuminating mixed microalgal culture to treat municipal wastewater," WIT Trans. Ecol. Environ., vol. 178, pp. 263-270, 2013.

[11] L. Sun, W. Zuo, Y. Tian, J. Zhang, N. Liu, J. Sun, and $\mathrm{J}$. Li, "Performance and microbial community analysis of an algal-activated sludge symbiotic system: Effect of activated sludge concentration," J. Environ. S, vol. 76, 2018.

[12] S. Zhu, L. Qin, P. Feng, Z. Shang, C. Wang, and Z. Yuan, "Treatment of low $\mathrm{C} / \mathrm{N}$ ratio wastewater and biomass production using co-culture of Chlorella vulgaris and activated sludge in a batch photobioreactor," Bioresour. Technol., pp. 1-37, 2018.

[13] M. B. Benítez, P. Champagne, A. Ramos, A. F. Torres, and V. Ochoa-Herrera, "Wastewater treatment for nutrient removal with Ecuadorian native microalgae," Environ. Technol., pp. 1-9, 2018.

[14] F. Marazzi, M. Bellucci, S. Rossi, R. Fornaroli, E. Ficara, and V. Mezzanotte, "Outdoor pilot trial integrating a sidestream microalgae process for the treatment of centrate under non optimal climate conditions," Algal Res., vol. 39, p. 101430, 2019.

[15] A. Anbalagan, S. Schwede, C. Lindberg, and E. Nehrenheim, "Influence of hydraulic retention time on indigenous microalgae and activated sludge process," Water Res., 2016.

[16] N. Mezzomo and S. Ferreira, "Carotenoids Functionality, Sources, and Processing by Supercritical Technology: A Review," J. Chem., pp. 1-16, 2016.

[17] J. Braniša, Z. Jenisová, M. Porubská, K. Jomová, M. Valko, and R. Klaudia, "Spectrophotometric determination of chlorophylls and carotenoids. An effect of sonication and sample processing," J Microbiol Biotech Food Sci, vol. 3, no. 2, pp. 61-64, 2014.

[18] M. Butnariu, "Methods of Analysis (Extraction, Separatio , Identification and Quantification) of Carotenoids from Natural Products Journal of Ecosystem \& Ecography," J. Ecosyst. Ecography, vol. 6, no. 2, pp. 61-64, 2016.

[19] A. Silva, J. Rocha, and M. Henriques, "Extraction and quantification of pigments from a marine microalga: A simple and reproducible method Extraction and quantification of pigments from a marine microalga: a simple and reproducible method," Commun. Curr. Res. Educ. Top. Trends Appl. Microbiol., pp. 586-593, 2007.

[20] M. Felip and J. Catalan, "The relationship between phytoplankton biovolume and chlorophyll in a deep oligotrophic lake: decoupling in their spatial," J. Plankton Res., vol. 22 , no. 1 , pp. 91-105, 2000.

[21] S. Jeffrey and G. Humphrey, "New Spectrophotometric Equations for Determinating Chlorophylls a, b, c1 and c2 in Higher Plants, Algae and Natural Phytoplankton," Biochem. Physiol. Pflanz., vol. 167, pp. 191-194, 1975.

[22] C. Butterwick, S. Heaney, and J. Talling, "A comparison of eight methods for estimating the biomass and growth of planktonic algae," Br. Phycol. J., vol. 17, pp. 69-79, 1982.

[23] H. Schmid, F. Bauer, and H. Stich, "Determination of algal biomass with HPLC pigment analysis from lakes of different trophic state in comparison to microscopically measured biomass," J. Plankton Res., vol. 20, no. 9, pp. 1651-1661, 1998.

[24] M. H. M. Ilyas, T. Havarasi, D. Pandiaraj, and D. MubarakAli, "Evaluation of Efficient Methods for Recovery of Photosynthetic Pigments from Microalgae," Pakistan J. Biol. Sci., vol. 15, no. 18, pp. 883-888, 2012.

[25] K. Wiltshire, M. Boersma, A. Möller, and H. Buhtz, "Extraction of pigments and fatty acids from the green alga Scenedesmus obliquus (Chlorophyceae)," Aquat. Ecol., vol. 34, pp. 119-126, 2000 .

[26] G. O. L. Pedruzi, M. L. Amorim, R. R. Santos, M. A. Martins, and M. Vaz, "Biomass accumulationinfluencing factors in microalgae farms," Rev. Bras. 
Eng. Agrícola e Ambient., vol. 24, no. 2, pp. 134-139, 2020.

[27] G. Gadd, "Biosorption: critical review of scientific rationale , environmental importance and significance for pollution treatment," J Chem Technol Biotechnol, vol. 84 , pp. 13-28, 2009 .

[28] W. Alalayah, Y. Alhamed, A. Al-Zahrani, and G. Edris, "Experimental investigation parameters of hydrogen production by algae chlorella vulgaris," in International Conference on Chemical, Environment \& Biological Sciences, 2014, pp. 41-43.

[29] S. Arnas, "Cultivating Algae in a Photobioreactor: Synthetic wastewater nutrient removal and carbon capture efficiency using the green algae species Chlorella pyrenoidosa," Helsinki Metropolia University of Applied Sciences, 2016.

[30] A. Wellburn, "The Spectral Determination of Chlorophylls a and b, as well as total Carotenoids, Using Various Solvents with Spectrophotometers of Different Resolution," J. Plant Phyisol., vol. 144, pp. 307-313, 1994.

[31] B. Desortova, "Relationship between Clrlorophyll Concentratíon and Phytoplankton Biomass in Several Reservoirs in Czechoslovakia,"Int. Rev. ges. Hydrobiol., vol. 66 , no. 2 , pp. $153-169,1976$.

[32] R. Mencfel, "Relationship among Biomass of Algae and Concentration of Chlorophyll a, against the Taxonomic Structure of Phytoplankton in Three Lakes on Lublin Polesie Region," Teka Kom. Ochr. Kszt.?rod. Przyr. -OL PAN., vol. 10, pp. 243-249, 2013.

[33] I. Krustok, "Microbiological analysis of municipal wastewater treating photobioreactors," Dissertation No 196. Mälardalen University, 2016.

[34] L. J. Rebecca, S. Sharmila, M. P. Das, and C. Seshiah, "Extraction and purification of carotenoids from vegetables," J. Chem. Pharm. Res., vol. 6, no. 4, pp. 594-598, 2014.

[35] S. Pacheco, F. Peixoto, R. G. Borguini, and S. De Mattos, "icroscale extraction method for HPLC carotenoid analysis in vegetable matrices," Sci. Agric., vol. 71, no. 5, pp. $345-355,2014$

[36] V. M. Paradiso, M. Castellino, M. Renna, P. Santamaria, and F. Caponio, "Setup of an Extraction Method for the Analysis of Carotenoids in Microgreens," Foods, vol. 9 , no. 459 , pp. 1-12, 2020 . 